\title{
CORPO FEMININO: ANÁLISE DOS REFLEXOS DAS TRANSFORMAÇÕES CORPORAIS NA CAPACIDADE DECISIONAL
}

\author{
FEMALE BODY: ANALYSIS OF THE REFLECTIONS OF BODY \\ TRANSFORMATIONS IN DECISIONAL CAPACITY
}

\section{Ananda Ayres Navarro ${ }^{1}$ Heloisa Silva Alves², Sonalyana Jales Varelo ${ }^{3}$, Loreley Gomes Garcia $^{4}$}

1 Universidade Federal da Paraíba, Departamento de Serviço Social, Brasil, e-mail: ananda.ayres@gmail.com, ORCID: https://orcid.org/0000-0002-5540-4681

2 Universidade Federal da Paraíba, Departamento de Serviço Social, Brasil, e-mail: heloisa silvaalves@hotmail.com, ORCID: https://orcid.org/0000-0003-2266-9293

3 Universidade Federal da Paraíba, Departamento de Serviço Social, Brasil, e-mail: sonaly.jales@hotmail.com, ORCID: https://orcid.org/0000-0002-2325-0147

$4 \quad$ Universidade Federal da Paraíba, Departamento de sociologia, Brasil, e-mail: loreleygg@gmail.com, ORCID: https://orcid.org/0000-0003-2170-4317

\author{
ARTICLE INFO \\ Article history: \\ Received 2020-06-01 \\ Accepted 2020-11-30 \\ Available online 2020-11-30
}

Palavras-chave: Corpo. Decisão. Escolha. Gênero.

Keywords: Body. Decision. Choice. Genre.

RESUMO. A temática sobre o universo feminino permanece necessária mediante o modelo opressor vigente na contemporaneidade, no qual a sociedade sexista continua influenciando diretamente na vida das mulheres. O trabalho questiona alguns aspectos biológicos, psicológicos e comportamentais na fase de transição da infância para adolescência, tendo em vista que percebe-se a associação desses elementos com a reprodução social misógina do sodalício. Tendo em vista essa vigência, o corrente artigo objetiva discorrer acerca da discussão de gênero, pautada no processo da autonomia decisional sobre o corpo de garotas cuja faixa etária é direcionada a idade dos 14 aos 18 anos. Nessa perspectiva, a pesquisa é desenvolvida a partir da obtenção de referenciais teóricos atrelados a aplicação de questionários após as oficinas de defesa pessoal ofertadas pelo grupo de pesquisa Pandora. Tal metodologia permitiu a obtenção de dados qualitativos e quantitativos baseados no poder de decisão sobre o corpo. Com base no exposto, o corpo feminino é reflexo de agregações sociais, que carecem de compreensão e discussões para que o processo de autonomia e empoderamento feminino sejam impulsionados.

\begin{abstract}
Female's universe thematic remains necessary due to an oppressive model current in contemporary times, in which the sexist society continues to directly influence in women's lives. The work questions some biological, psychological and behavioral changes during the transition from childhood to adolescence, considering that the association of these elements with misogynistic social reproduction of sodalice is perceived. In view of this validity, the current article aims to discuss the gender discussion, guided by the process of decision-making autonomy over the body of girls whose age range is age from 14 to 18 years. In this perspective, the research is developed from obtaining theoretical references linked to the application of questionnaires after the workshops self-defense offered by the Pandora research group. Such methodology allowed to obtain qualitative and quantitative data based on the decision power over the body. Finally, the female body is a reflection of social aggregations, which lack understanding and discussions so that the process of autonomy and female empowerment are boosted.
\end{abstract}




\section{Introdução}

O período de passagem da infância à adolescência é um momento que merece ser discutido, tendo em vista, as diversas modificações que o caracteriza. Nas mulheres, esta fase, é biologicamente identificada de menarca, demarcada pela primeira menstruação, ou seja, amadurecimento corporal oriundo da puberdade e início da vida reprodutiva. Nesse sentido, a menarca como um processo de passagem, reflete em alterações fisiológicas, psicológicas e comportamentais de maneira que a partir das interações hormonais, observase a modificação nos corpos femininos que podem refletir tanto na reação de si mesmo com o próprio corpo, quanto na maneira encarada pela sociedade.

Portanto, tendo em vista esta repercussão, o presente artigo objetiva a abordagem e compressão do corpo feminino, a partir de considerações da autonomia decisional sobre o corpo de garotas cuja faixa etária é direcionada a idade dos 14 aos 18 anos. Para isso, a pesquisa é desenvolvida a partir de uma análise qualitativa e quantitativa, baseada em referenciais teóricos atrelados a aplicação de entrevistas. Além disso, são ofertadas oficinas objetivando suprir, através de discursos e aulas de defesa pessoal, as carências de compreensão e reconhecimento das jovens com seus próprios corpos de maneira que estimule autonomia e empoderamento feminino em seus respectivos cotidianos.

\section{Desenvolvimento}

\section{I - Metodologia}

Para obter os resultados e respostas acerca da discussão apresentada, realizou-se uma pesquisa de caráter exploratório descritivo constituída por pesquisa de revisão bibliográfica, na qual o grupo de pesquisa Pandora se reunia quinzenalmente para discutir apontamentos que basearam a investigação. Em consonância a isso, efetivou-se a ação empírica através da atividade em campo, tanto com a oferta de oficinas quanto com a aplicação de questionários.

As oficinas aconteceram em diversas localidades brasileiras, com maior foco no Nordeste, sendo elas: Baía da Traição (PB), Cabedelo(PB), Gramame (PB), Jardim Veneza (PB) e Santos (SP). De maneira geral, objetivavam promover entendimentos baseados no poder de decisão sobre o corpo. Para tanto, eram compostas por diálogos e aula de Wendo luta de defesa pessoal feminista- a qual estimula o corpo enquanto instrumento de defesa para possíveis enfrentamentos. 
Ao término dessas atividades eram realizadas entrevistas não obrigatórias com algumas das entrevistadas. Dessa maneira, foram coletados cerca de oito questionários em cada localidade. É importante constatar que os critérios de participação se delimitavam em: ter de 14 a 18 anos; pertencente ao sexo feminino e ter participado das vivências propostas pelo grupo. Nessa perspectiva, no decorrer do trabalho, serão expostas as principais considerações deste estudo de caso relacionando com os dados coletados.

\section{II - Influência na construção de escolhas a partir das orientações do "Lar"}

$\mathrm{Na}$ fase transicional, de adolescer, em que ocorre a passagem da infância à adolescência, o corpo, biologicamente se modifica rapidamente, demandando um desenvolvimento psíquico e comportamental na mesma velocidade, de maneira que induz a definição de um papel à menina enquanto integrante de um círculo social. Essas transformações permitem às jovens experiências ao desconhecido, no sentido de que mesmo que permaneçam mentalmente infantis, encaram além de mudanças corporais, novas sensações incontroláveis. Exemplo disso, são as cólicas e tensões pré-menstruais que influenciam na incompreensão de si mesmo, enquanto mulher e do seu lugar em sociedade.

Em suma, a partir da menarca, as relações sociais, reproduzem um novo status às meninas, objetivando moldá-las a certos elementos femininos. Ou seja, baseada em uma lógica patriarcal e arcaica, a sociedade dissocia determinações e concepções sexistas que delineiam o que comumente denomina-se de "mocinha". A partir das pesquisas realizadas em campo, recolheu-se muitos resultados em que as jovens entrevistadas associavam esse período a maior determinação de responsabilidades e designações por conta da família.

A sociedade é composta por instituições que guiam o regime e a forma de orientação de todos, sendo assim, as mesmas ocupam diferentes lugares de formas distintas, mas todos com o viés doutrinário. O primeiro contato que o ser humano se encontra, é de fato a instituição familiar, a qual se compreende preservar o os bons hábitos familiares que alguns são passados por gerações e outros sendo modificados pelo tempo, outro assim, é a instituição de maior influência de nossas vidas, mesmo que hajam descordos, sempre será a primeira forma de interação social.

A família em si a grosso modo, trata de um grupo de indivíduos que dividem o mesmo teto, como pai e filho. Tendo essa perspectiva sobre família, nos deparamos com o lar, que é o local onde o indivíduo mora, para isto se compreende que o esse espaço é o ambiente de maior interação da pessoa, em que (Osório, 1996) "Sendo um modelo ou um padrão cultural que se apresenta de formas diferenciadas nas várias sociedades existentes e que sofre transformações no decorrer do processo histórico-social".

Sendo assim, a partir do questionário aplicado com as adolescentes, compreende a ideia de que o lar influencia as decisões das garotas principalmente por meio das orientações de suas referências de poder e autonomia dentro dos lares. A primeira observação que pode 
ser notada é quando se questiona "Quem é chefe de família?" pois verifica-se que a adolescente tende a ter uma maior independência, quando os pais são separados por ter a figura da mãe como maior influência, entretanto se comparada a lares compostos por representações de mãe e pai, em grande maioria da entrevista consta o poder de decisões finais a representação do Pai, mesmo que a mãe seja a chefe nas atividades domésticas do dia a dia, a figura paterna representou maior índice de autoridade, gerando uma certa influência e limitações nas escolhas das jovens por não vivenciar a autonomia da feminina no próprio lar.

Para além disso, se encontram outras instituições que incidem dentro dos lares como a cultura, economia e religiosidade da família, que faz com que a adolescente tenha esse primeiro contato com outras instituições de formas direcionada. Vale ressaltar outra grande instituição que influencia principalmente neste período da adolescência que são as escolas, a qual a família é quem escolhe para as jovens.

Contudo as limitações de casa também passam para espaços próximos de seus lares como a calçada, a qual desde as primeira interações de escolhas de quais colegas de ruas as crianças devem brincar, se perduram até das orientações de 'boas amizades' que essa instituição familiar direciona, pois dentro da pesquisa tem-se a visualização de que no passar para a adolescência, as meninas se encontram em um espaço reduzido sem tanta liberdade pelo ponto de vista que se encontram em uma nova fase de amadurecimento, em que antes se vislumbra um imenso espaço para interações e brincadeiras mesmo que de forma monitorada, nessa mudança elas detém de uma percepção de que a vida a qual já se iniciam (fase da adolescência) parte para uma preparação para sua função social de reprodução da espécie.

\section{III - Mulher construída socialmente para "formar" uma família}

Dialogar com adolescentes é uma verdadeira surpresa, pois identificar por meio de expressões e no discurso onde realmente podemos aproveitar de sua fala se faz necessário ter zelo com o momento da entrevista. Algumas das perguntas nos permitem compreender melhor o que se passa na sua vida de modo geral e suas decisões.

Seu corpo absorve alguns reflexos que a vida direciona, tendo em vista alguns direcionamentos pré-determinados socialmente para elas. As funções as quais se restringem permite identificar o lugar de seus corpos em suas casas, as mães que são direcionadas para serem chefes de casa sem autonomia e que acabam se limitando no espaço cozinha, direciona para as jovens até onde podem alcançar desde os espaços dos seus próprios lares.

Um dos grandes fatores que a sociedade induz é por meio da divisão de funções pelo gênero, que se faz como um dos pontos que normaliza os comportamentos esperados paras as mulheres, esse fato ocorre por meio de uma certa aprendizagem social que foi construída 
por anos, mesmo que ela se modifique dependendo da forma com que a cultura daquele local ou região foi construída. Essas plataformas sociais direcionam para uma redução de ideias diretamente assumidas como efeito normativo, que para isto, as entrevistas fazem papel de compreender como elas traduzem essas funções designadas para seus corpos.

Ao analisar as entrevistas, é notório o quanto a mulher é sobrecarregada de funções para manter a família, encontra-se diversas respostas quando se questiona "Qual o papel da mulher e do homem?", dentre as respostas obtivemos:

"R1: Bom, o da mulher ... meu pensamento é meio antigo. A mulher é tipo: a casa, mas tem seus direitos também."

"R2: Estar do lado do homem, suportar as coisas da vida"

"R3: A mulher é a base porque mesmo trabalhando fora de casa, ela ainda tem que fazer muitas coisas em casa. O homem é mais como um papel de auxílio e ajuda."

"R4: E: Homem é machista. Mulher tem que trabalhar, cuidar da casa e dos filhos."

"R5: O papel do homem é trabalhar pra ajudar nas despesas e ajudar nas tarefas diárias. $O$ da mulher é cuidar do lar."

Essas são algumas das respostas que as adolescente responderam, sendo assim, podemos observar o quanto a maioria ainda tem um pensamento voltado para essa sobrecarga que a mulher tem de conduzir a estrutura e moldar a família, mesmo que exerça múltiplas funções - o que deveria ser dividido/compartilhado - se entende que é um 'mal' necessário para bem vizinhança dos olhares externos por atender dentro dos parâmetros as atividades socialmente condicionadas.

\section{IV - Capacidade decisional sobre o corpo: aborto}

Falar sobre o aborto ainda engloba uma série de preconceitos e tabus para que essa discussão não seja levada em consideração, tendo em vista que instituições familiares e religiosas, recriminam de forma excessiva o ato de abortar. Em meio a tantas intervenções da sociedade nesse ponto de escolha que deveria ser principalmente da mulher que realizaria 0 ato, se encontram contraposições da capacidade de escolha das meninas, tendo em vista que mundialmente o aborto é conhecido como um problema de saúde pública.

Ampliando o olhar para realmente observar a opinião de quem realmente vai viver todo esse 'trâmite', enxergarmos para além disso todas as críticas que podem influenciar essas jovens, quando escutam comentários como: "Vai atrasar sua vida" ou "Você foi inconsequente", pois todo esse processo de julgamento e culpabilização da mulher se torna exclusividade dela e ao questionar as possibilidades de rumo que sua vida irá tomar, as jovens geralmente se encontram com três opções, sendo elas: Aborto, casamento por conveniência e ser mãe solteira.

Certamente a maternidade é um ponto importante a ser discutido na vida de uma mulher, tendo em vista que marca e transforma por se tornar uma mãe. É visto que as meninas 
se sentem inseguras em relação a esse tema, a insegurança de deixar projetos de vida de lado e sobre o aborto. Esse posicionamento incerto das jovens é um reflexo da pressão de dever dar satisfação para toda sociedade, em que acaba interferindo diretamente na sua escolha.

A análise dos dados trouxe muitas incertezas e a maioria apontou que suas escolhas dependerão de opinião, momento ou escolha de outra pessoa - se estivesse em seu lugar -. Muitas apontam que não abortaram, mas ainda existem meninas que deixaram respostas de dúvidas como: sei lá, tornando sua opinião não muito concreta e certa das suas escolhas. Sendo assim algumas das respostas sobre se fariam o aborto, foram:

"B1: Eu não abortaria, pois a criança não tem culpa de nada."

"B2:Não sei, acho que por conta da minha mãe talvez eu abortasse, ela me mataria se soubesse."

"B3: Deixaria, acho que abortar é um crime pois é uma vida dentro de você. Se fiz, foi um deslize e teria que arcar com as responsabilidades."

"B4: Não aborto não, isso é errado, uma criança não pediu para nascer, foi fez aquilo porque quis."

"B5: Eu deixaria porque tenho medo de morrer"

O medo, insegurança e certezas sociais estão instaurado no cotidiano das meninas, o que afeta diretamente as suas escolhas com o seu corpo, por de fato mudar psicologicamente, fisicamente e de um modo geral de sua vida, outro assim, entre o processo de escolha entre maternidade e o aborto, existe um grande precipício de ideias e pensamentos, que muitas sentem incertezas e medo de como poderá afetar suas vidas.

\section{Resultados e Discussão}

Ao longo da aplicação da entrevista, ficou evidente o constrangimento que por muitas vezes foi gerado a partir do olhar direcionado ao corpo das participantes. Os relatos sobre o medo que a mudança no corpo gerou, a responsabilidade que ele as trouxe e as modificações no comportamento que elas tiveram se destacam nas perguntas "Quando era menina o que costumava fazer? O que deixou de fazer quando chegou a adolescência?", "Ter um corpo diferente te incomodou? Olhares, assédios, que sentimentos causaram?" e "Você já passou por alguma situação desagradável? Assédio? Constrangimento? Alguma situação desconfortável pelo fato de ser uma garota? Qual foi e como reagiu?".

A percepção de que a partir da mudança no corpo as meninas passaram a também adquirir responsabilidades, reforça o padrão patriarcal de que a partir dali, elas estariam preparadas para assumir algumas obrigações que anteriormente não eram suas atribuições, as brincadeiras agora fazem parte do seu passado. Além disso, as privações que agora elas 
vivenciam pelo gênero, reforça o machismo que as rodeia, intensificando a noção de que a partir de agora elas devem ser cuidadosas consigo mesmas e que elementos que anteriormente eram rotineiros, agora são perigosos, tornando-as assim, vulneráveis, visto que, os olhares a elas direcionados agora representam uma ameaça.

Dessa forma, intensifica-se a erotização sob as jovens. São diversos os relatos das entrevistadas que dissertam sobre a percepção de que a partir das modificações corporais, com a chegada à adolescência, aumentam-se os níveis de assédios enfrentados cotidianamente por elas. A alternância do olhar fraterno ao olhar com desejo é outra problemática, uma vez que ao questionadas "você prefere ser bonita ou ser gostosa?" a preferência pelo ser bonita prevalece. Analisando suas colocações, é evidente que ser gostosa em uma sociedade em que chamam atenção pelo corpo independente de como ele seja e que as julga pelo que aparentam, ser gostosa significaria um olhar ainda mais intenso e amedrontador sobre seus corpos. Com isso, é perceptível o quanto os pares e a sociedade, de modo geral, têm influências sobre seus corpos, ainda que na perspectiva do medo.

Nesse sentido, baseado nas entrevistas, quando referente às mudanças corporais, as adolescentes se encontram em um momento de inquietações e incômodos. Praticamente todas meninas entrevistadas, associam a fase à falta de liberdade, surgimento de indecisões e dúvidas. Assim, pode-se perceber o quanto a sociedade é omissa nos enfrentamentos a esses pontos. A menstruação e sexualidade permanecem como um tabus na sociedade, de maneira que certas inquirições necessitam ser respondidas individualmente, ou dinamizadas para outros níveis de sociabilidade, superando o nível familiar e atingindo assim, outros núcleos de convivência, como no âmbito escolar: em aulas e palestras.

No mais, as oficinas juntamente com as discussões promovidas geram um impacto instantâneo perceptível na vida dessas adolescentes. Para além do brilho nos olhos na hora da saída, a sensação de empatia que permeia a sala que ocupam e o segredo que guardam juntas, saber que agora elas terão subsídios caso se sintam extremamente ameaçadas, gera nelas empoderamento e confiança.

Em suma, análises como as abordadas ao longo da pesquisa apresentada, evidenciam que a sexualidade ainda é um tabu para a sociedade, principalmente quando direcionadas ao sexo feminino. Nesse sentido, é importante compreender que ainda que as decisões das adolescentes entrevistadas digam respeito aos seus corpos, por vezes elas contém influências de terceiros. Portanto, percebe-se a necessidade de medidas que promovam um maior conhecimento e aceitação do seu corpo, e para além disso, a superação dos enfrentamentos sexistas impostos pela sociedade, tendo em vista seus questionamentos diante das suas mudanças corporais. 


\section{Conclusão}

Com base nas exposições, percebe-se que a maneira que as meninas são preparadas, pode exercer impacto sobre sua reação com as transformações e logo, com o corpo. Assim, o significado da menarca para as jovens está carregado de sentimentos e questionamentos decorrentes de uma cultura que não valoriza o diálogo e o conhecimento das questões referentes ao corpo.

Nesse sentido, a capacidade do corpo enquanto forma de força e resistência contra as condições impostas pela sociedade, devem ser difundidas. Uma vez que, a partir da experiência com as oficinas, garotas se empoderaram a respeito de si mesmas enquanto um instrumento capaz de se defender e reagir, respeitando suas vontades e escolhas independente das imposições do meio. Essas determinações de autonomia são transferidas ao âmbito de ação de seus cotidianos de maneira que suas vontades passam a ser realizadas a partir do seu próprio desejo. Em uma sociedade patriarcal e arcaica demarcada historicamente a invisibilidade do sexo feminino, elementos como esse merecem ser difundidos.

Portanto, torna-se evidente o quanto o sexo ainda permanece como um tabu nas famílias brasileiras. De maneira que discussões como essa são importantes na contemporaneidade. Assim, percebe-se a importância da dinamização desse diálogo entre jovens e a temática a respeito de sexualidade em ambientes educativos e familiares capazes de promover compreensões a respeito de estupro, gravidez, métodos contraceptivos e consequentemente, conhecimentos a respeito do corpo

\section{Agradecimentos}

Primeiramente, gostaríamos de agradecer ao grupo de pesquisa Pandora, o qual através da pesquisa desenvolvida, proporcionou conhecer tantas histórias de meninas sonhadoras e guerreiras, assim como nos inseriu como pesquisadoras, incentivou e permitiu inúmeras experiências inesquecíveis. Outrossim, agradecemos a todas instituições e profissionais parceiros que nos proporcionaram os encontros com as jovens, desde ceder o espaço para realização das as oficinas e até mesmo a logística pensada dentro das instituições, para convidar as entrevistadas a participarem deste momento. Sendo assim, agradecemos em especial ao Instituto Federal da Paraíba - Sede Cabedelo, Instituto Federal 
de São Paulo - Santos, ao PSF - Bairro Várzea Nova e Prefeitura de Baía da Traição, que dentre tantas instituições foram algumas das nossas parceiras nesse projeto.

\section{REFERÊNCIAS}

BRANDÃO, E. (2006) Gravidez na adolescência um balanço bibliográfico In: HEILBORN, Maria Luiza et.al. $O$ aprendizado da Sexualidade: reprodução e trajetórias sociais dos jovens. Rio de Janeiro: Garamond e Fiocruz, 2006.

BRÊTAS, J; TADINI, A; FREITAS, M; GOELLNER, M. Significado da menarca segundo adolescentes. São Paulo. 2011. Disponível em: , Acesso em: 16. Ago. 2019.

GIDDENS, A. Sociologia. 4ae edição. São Paulo. ARMED editora.2001.

BORGES, R. (1999) Gravidez na Adolescência e Reconhecimento Social Estudo de Caso entre adolescentes grávidas no Bairro Saco Grande/Monte Verde, zona urbana de Florianópolis, Dissertação UFSC.

CALDIZ, L. S., MALOSETTI, L. e BAYARDO, R. (1994) Maternidade adolescente em Baloche (Argentina) In: COSTA, A., AMADO, T. (org). Alternativas Escassas; Saúde, Sexualidade e Reprodução na América Latina. São Paulo: PRODIR/Fundação Carlos Chagas: Rio de Janeiro: Ed. 34.

CARNESECCA, Maria do Carmo Quinello. As mulheres adolescentes de Araraquara: sáude reprodutiva, maternidade e gênero. Dissertação de mestrado - Universidade Estadual Paulista, Araraquara, 1998.

DESSER, N. (1993) Adolescência Sexualidade e Culpa. Brasília: Rosa dos Tempos-UNB Eisenstein E. Adolescência: definições, conceitos e critérios . Adolesc Saude. 2005;2(2):6-7 FÓRUM BRASILEIRO DE SEGURANÇA PÚBLICA(FBSP)e Instituto Data Folha (2017) Visível e invisível: a vitimização de mulheres no Brasil.

GIDDENS, A. (1984). The Constitution of Society: Outline of the Theory of Structuration. Berkeley: University of California Press. GILL, R. (2003) From sexual objectification to sexual subjectification: The sexualization of women's bodies in the media. Feminist Media Studies $3(1)$

GIDDENS, A. Sociologia. 4ª edição. São Paulo. ARMED editora.2001.

MACHADO, M.D. e BARRO, M. (2009) Gênero, geração e classe: uma discussão sobre as mulheres das camadas médias e populares do Rio de Janeiro. Estudos Feministas, Florianópolis, 17(2)

PAIVA A.N., CALDAS M. e CUNHA A. (1998) Perfil psicossocial da gravidez na adolescência. In: Monteiro, Cunha e Bastos (orgs). Gravidez na adolescência. Ed. Revinter, Rio de Janeiro. 
PANTOJA, A. L. (2003) "Ser alguém na vida": uma análise sócio antropológica da gravidez. PRATTA, Elisângela Maria Machado; SANTOS, Manoel Antonio. Família e adolescência: a influência do contexto familiar no desenvolvimento psicológico de seus membros. Maringa. 2007. Disponível em: < http://www.scielo.br/pdf/pe/v12n2/v12n2a05> , Acesso em: 16. Ago. 2019.

SANDI, Stella de Faro; BRAZ, Marlene. As mulheres brasileiras e o aborto: uma abordagem bioética na saúde pública. 2010. Disponível em: http://www.revistabioetica.cfm.org.br/index.php/revista_bioetica/article/view/541/527>,Acess o em: 18. Ago. 2019.

SOUZA, Eros. A Construção Social dos Papéis Sexuais Femininos. 2000. Disponível em: Acesso em: 18. Ago. 2019.

SOUZA, Eros. A Construção Social dos Papéis Sexuais Femininos. 2000. Disponível em:\&lt;http://www.scielo.br/pdf/prc/v13n3/v13n3a16\&gt; Acesso em: 18. Ago. 2019.

THERBORN, G. (2006) Sexo e poder: a família no mundo: 1900-2000. São Paulo: Contexto. 